\title{
Treating Adolescents Together or Individually? Issues in Adolescent Substance Abuse Interventions
}

\author{
Tracy A. O’Leary, Sandra A. Brown, Suzanne M. Colby, Jessica M. Cronce, Elizabeth J. D’Amico, Jonathan S. Fader, \\ Irene M. Geisner, Mary E. Larimer, Jennifer L. Maggs, Barbara McCrady, Rebekka S. Palmer, \\ John Schulenberg, and Peter M. Monti
}

\begin{abstract}
This article summarizes the proceedings of a symposium, chaired by Peter Monti and cochaired by Tracy O'Leary, that was presented at the 2001 RSA Meeting in Montreal, Quebec. The aim of this symposium was to present data on group- and individual-based interventions for adolescent alcohol and substance abuse, with a discussion of the implications of research findings bearing on developmental considerations when working with adolescents and young adults. Elizabeth J. D'Amico, PhD, reviewed recent findings on adolescents' choice of type of substance abuse treatment. Jennifer L. Maggs, PhD, presented a developmental perspective on this issue. Tracy O'Leary, $\mathrm{PhD}$, presented data on enhancing motivational interviewing with the presence of a supportive peer for college students cited for alcohol infractions. Mary E. Larimer, PhD, presented 1-year follow-up results of the Greeks 2000 Project, a 5-year longitudinal study designed to evaluate the efficacy of an alcohol abuse prevention program provided to college students who were entering a pledge class (first year) of Greek houses. Barbara McCrady, $\mathrm{PhD}$, a noted expert on the treatment of couples for substance abuse problems, served as discussant.
\end{abstract}

Key Words: Adolescent, Alcohol, College Student Drinking, Intervention.

\section{ADOLESCENT SELF-SELECTION OF GROUP AND INDIVIDUAL FORMATS: IMPLICATIONS FOR ALCOHOL INTERVENTIONS}

\section{Sandra A. Brown and Elizabeth J. D'Amico}

Alcohol is the most commonly used drug among adolescents, with approximately $50 \%$ of high school seniors reporting use in the past 30 days and one third reporting heavy drinking behavior (e.g., five or more drinks on one occasion) in the previous 2 weeks (Johnston et al., 2000). Although many youths experience problems resulting from

From the Center for Alcohol and Addiction Studies (TAO, SMC, PMM), Brown University, Providence, Rhode Island; the Department of Psychology (SAB, EJD), University of California, San Diego; Psychology Service, Veterans Affairs San Diego Healthcare System, La Jolla, California; the Department of Psychology (JMC, JSF, IMG, MEL, RSP), University of Washington, Seattle, Washington; the School of Family and Consumer Sciences (JLM), the College of Agriculture and Life Sciences, University of Arizona, Tucson, Arizona; the Center of Alcohol Studies (BM), Rutgers, The State University of New Jersey, Piscataway, New Jersey; and the Institute for Social Research (JS), University of Michigan, Ann Arbor, Michigan.

Received for publication January 7, 2002; accepted March 11, 2002.

Supported by the NIAAA (Grants AA0703 and AA12171), the Center for Substance Abuse Treatment, and the VA Medical Research Program (SAB); the Alcoholic Beverage Medical Research Foundation and the University of Arizona Agricultural Station (JLM); a Research Excellence Award from the Center for Alcohol and Addiction Studies, Brown University, and Grant R01 AA12319-01 from the NIAAA (TAO); and Grant R01 AA10772-5, Prevention of Alcohol Problems in College Greek Systems, from the NIAAA (MEL).

Reprint requests: Tracy A. O'Leary, PhD, Center for Alcohol and Addiction Studies, Brown University, Box G-BH, Providence, RI 02912; Fax: 401-444-1848; E-mail: tracy_o'leary@brown.edu

Copyright (C) 2002 by the Research Society on Alcoholism. their alcohol involvement, few voluntarily seek treatment in currently available programs (Brown, 1993), which are often derivatives of programs designed for adults (Deas et al., 2000). Recent studies suggest that the alcohol-consuming youth most in need of intervention services may be the least likely to initiate formal treatment (e.g., Windle et al., 1991).

We have hypothesized (Wagner et al., 1999) that voluntary engagement of youth in alcohol services requires sensitivity to developmental issues and consideration of youth preferences. For example, factors influencing voluntary participation of adolescents in alcohol programs included socially acceptable formats, perception of helpfulness, and accessibility. Further, as Deas et al. (2000) note, adolescents who drink regularly progress more rapidly to alcohol problems than do adults, providing a shorter window for engaging youth in secondary intervention efforts.

Brief interventions seem well suited for youth and have shown promise in reducing both adolescent drinking and adverse alcohol consequences (e.g., Breslin et al., 1998; D'Amico and Fromme, 2000; Monti et al., 1999). Although brief interventions for adolescent alcohol problems are relatively new, they have been implemented in several different settings, including high schools (Brown, 2002; D'Amico and Fromme, 2000) and emergency rooms (Monti et al., 1999). However, at present there is no evidence regarding optimal formats for secondary interventions for adolescent alcohol involvement and little information regarding youth preferences for intervention formats.

Developmentally focused researchers have suggested advantages of both group and family formats for adolescent 
treatment. The influence of peer relationships substantially increases during adolescence (Ary et al., 1993), and family involvement may facilitate both engagement and retention of youth in alcohol and drug treatment (Liddle and Dakof, 1995). Several studies have indicated that for deviant youth assigned to specific treatment, there may be possible iatrogenic effects of group intervention (Arnold and Hughes, 1999; Dishion et al., 1999). This may be due, in part, to verbal and nonverbal cues during the group session that operate to reinforce the deviant orientation of youths in the group.

Group interventions are often used with this age group because of their developmental relevance (Brown, 2002; Wagner et al., 1999). The group format substantially increases the opportunity for prosocial peer feedback and discussion, and there is potential cost-effectiveness of this format over individually delivered interventions. Furthermore, our previous research on youth self-change (D'Amico et al., 2002; Stice et al., 1998; Wagner et al., 1999) indicates that adolescents who stop drinking without formal treatment use a variety of strategies to reduce or stop drinking, including individual efforts (e.g., willpower), structured activities (e.g., recreation), and social resources (e.g., support groups and friends). Thus, in certain circumstances group involvement may facilitate reductions in drinking, whereas other group contexts may socialize youth into greater deviance. The iatrogenic effects of certain group interventions may reflect the forced nature of youth attendance, the composition of the group, the content or process within the group, the process of engagement, or a combination of these. To further explore the utility of the group format for secondary alcohol intervention, this study examined the rates of youth voluntary self-selection into three alcohol intervention formats: group, individual, and Web site. The multiple options for assistance in changing drinking patterns were made available at convenient times in high school settings to examine youth preferences for intervention formats via their service utilization patterns.

The intervention content and process were based on the developmental social information processing model of Coie and Dodge (1998). Within this framework, youth drinking decisions and behavior result from proximal cognitive and emotional states within a social context. Our brief intervention focused on increasing motivation for change (e.g., nondrinking), expanding resources for alternative behaviors, and building behavioral skills to increase the likelihood of personal change efforts. Components of the intervention included normative feedback, expectancy challenges, discussions of prevalent stressors among youth, identification of the personal need to change and selfmonitor drinking, and socially acceptable strategies to help communicate more effectively with peers, parents, and other authority figures, such as teachers. On the basis of prior research with high school students (e.g., Wagner et al., 1999), three intervention formats were selected: group discussion, individual sessions, and computer Web sites.
These formats were selected because they are readily available to and are perceived as helpful by youths, and they reflect the diversity of strategies youths use to successfully cut down or stop drinking. Six 30-min group sessions, four 30-min individual sessions, and unlimited Web site access were simultaneously promoted and offered at three high schools in metropolitan San Diego, CA. The content was similar across settings and incorporated issues identified through survey research at these sites as important to students. The intervention was implemented at each of the high school campuses to minimize barriers to involvement (e.g., convenient times and places) and to allow full choice by 4500 students (e.g., participate independently or with others) (D'Amico et al., 2001). Approximately 10\% ( $n=$ 492) of students at each high school participated in Project Options in the first academic year it was offered. Of the youths voluntarily using the secondary intervention, $80 \%$ used the group format, $5 \%$ selected the individual format, and $12 \%$ used the Web site. Students who self-selected into these different intervention formats were representative of the ethnic distributions at the high schools. Non-Hispanic white youths were more likely to participate in the group format, whereas a higher percentage of Asian and Hispanic adolescents chose to use the individual format. Of intervention participants, $67 \%$ were ninth and tenth graders, and younger students were more likely than upper-grade classmates to participate in the group format.

Several potential risk factors were also examined in a subset of students $(n=154)$ to determine whether these characteristics were associated with intervention participation. Students who self-selected into any of the three formats of Project Options did not differ from the total high school population on the survey measures of self-esteem, sensation-seeking, anxiety, or depression $(p>0.05)$. Intervention participants did significantly differ, however, from the high school sample on self-reports of feeling angry, frustrated, or irritated. Youth who self-selected into the intervention reported these feelings more frequently (19\%) than the general school sample $\left[11 \% ; \chi^{2}(1, n=154)=\right.$ $8.91 ; p<0.01]$.

In summary, our findings suggest that it is feasible to administer this type of self-selected intervention in a high school setting, because $10 \%$ of students across schools voluntarily attended the alcohol-related program. Participation in the three intervention formats varied by age and ethnicity. Psychological risk factors were not found to be associated with participation, with the exceptions of feelings of anger, irritation, and frustration. Our findings should be considered preliminary and in need of replication. As the program continues, we will assess whether decreases occur in drinking involvement among intervention participants relative to other high school students and, if so, for whom these changes occur (e.g., boys, Asians), how long such changes last, and which formats are most associated with maintenance of successful change for adolescent alcohol involvement. 
Is Alcohol Use Developmentally Normative? Paradoxical Correlates of Older Adolescent Drinking and Implications for Harm Reduction

Jennifer L. Maggs and John Schulenberg Alcohol use and heavy drinking are culturally embedded in the transition to young adulthood in general and in the college experience in particular. The prevalence of college students' alcohol use has changed little in two decades, despite many national and local prevention programs and policies. Moreover, passing through a transitional period of socially motivated heavy alcohol use is arguably a rite of passage for many students. However, the adolescent to young adult years are an important juncture in the etiology of adult alcohol abuse and alcoholism; simply, heavy experimental use during this time in life sets the stage for a lifelong struggle with alcohol for many.

Maggs and Schulenberg examined college students' alcohol use (and substance use in general) from a developmental-contextual perspective. Individual development was characterized by a dynamic and progressive mutual selection and accommodation of active individuals and their contexts or ecological niches. On the basis of personal goals and characteristics, individuals were assumed to actively select environments and activities that then exposed them to various developmental opportunities, influences, and constraints, a process known as niche-picking or as active genotype-environment interaction.

The study had three main aims: (1) to understand alcohol use in light of the culturally normative developmental tasks of the transition to college, focusing on personal goals in academic, friendship, and romantic arenas; (2) to examine processes of niche selection, that is, to what extent students' goals and adjustment predict Greek system and alcohol involvement; and (3) to assess possible context effects by contrasting the alcohol use of three groups of students: those who never had any interest in the Greek system (Nevers, 37\%), those who wanted to join but did not (Wannabes, 30\%), and those who joined (Joiners, 33\%). A cross-cutting theme is the paradox of risk-taking that focuses on the simultaneous potentially harmful and developmentally beneficial aspects of substance use and other problem behaviors (Maggs, 1997). On the basis of prior research, alcohol use and heavy drinking were hypothesized to be associated with markers of both psychosocial difficulties (e.g., low self-esteem, low academic goals) and psychosocial health (e.g., confidence, plans in the social arena).

Data from the University Life Transitions Orientation Survey ( $n=943 ; 2$ months before university enrollment) and the Telephone Interview Study $(n=202$; spring of freshman year) were used. Measures included academic, friendship, and dating goals; self-esteem; peer acceptance; Greek involvement; and alcohol use. Planned alcohol use was measured at orientation, and actual use was measured in a series of 10 weekly interviews 8 to 10 months later. Students' reports were averaged within-person across weeks to compute (1) the number of drinking days per week and (2) heavy drinking, the number of days per week students consumed more than four (for women) or five (for men) drinks.

On average, students endorsed the three domains of the developmentally normative goals highly. Friendship goals were endorsed more strongly than academic goals, which in turn were endorsed more strongly than dating goals. The median number of drinking days was 2.5 days/week; the median for heavy drinking was 0.5 days/week. Across 10 weeks of interviews, only $7 \%$ of students never drank any alcohol, and $22 \%$ never drank heavily.

Correlation/regression analyses showed that students who strongly endorsed getting good grades both planned to and did drink less often and less heavily. Academically oriented students were less likely to plan to join Greek organizations but did not differ in actual membership. Students who valued making friends planned to and joined Greek organizations at a higher rate, and they planned to and did drink more often and more heavily. Self-esteem did not predict Greek plans or membership. Students with lower self-esteem planned to drink more, but their actual consumption did not differ from that of students with higher self-esteem. Perceived peer acceptance was the most consistent and strongest predictor: students who at orientation felt more confident about peer relations were more likely to join the Greek system, drank more days per week, and drank heavily and more often.

These results are relatively consistent with the nicheselection hypothesis, as well as the prediction of paradoxical correlates. That is, students' academic and social goals predicted their alcohol use and Greek participation. Students who felt more confident with and accepted by their peers, arguably a positive and healthy attribute, were more likely to join the Greek system and to drink (heavily) more often. Students with lower self-esteem planned to drink heavily more often than other students, but their actual rates did not differ. One might speculate that these lowself-esteem students did not have sufficient confidence to achieve their alcohol use plans, or perhaps their plans were unrealistic.

Students who are involved in Greek student organizations have, on average, higher rates of heavy alcohol use. In these analyses, evidence of selection effects would be if students who wanted to join had heavier alcohol use than students who were never interested in joining. Evidence of context effects would be if students who were accepted and actually joined had higher alcohol use than those who planned to join but did not. Contrast-coded variables representing these two types of effects were added to the previous regression models. Results showed that Wannabes and Joiners drank (and drank heavily) more days per week than Nevers; this is consistent with selection effects. However, Joiners and Wannabes did not differ in the number of days they drank or in heavy drinking; this did not support context (or socialization) effects. 
The results in general are consistent with the assertion that individuals can shape their own behavior, whether consciously or not, through the influence of their goals and personal characteristics. It would seem that students who have an interest in drinking find ways to pursue this interest, whether they do this from inside or outside the formal social organization of the Greek system. Although evidence was not found for context effects, limitations of the analyses and design do not rule out this possibility.

A developmental perspective that takes seriously students' developmentally and culturally normative goals and tasks should have implications for prevention and health promotion (Schulenberg and Maggs, 2002). The discussion focused on prevention implications of the cultural embeddedness of heavy alcohol use during college that follow from these results and from a developmental perspective more generally. First, developmental transitions represent windows of opportunity for effecting change. Second, colleges may use niche-selection processes to promote more temperate drinking through institutional promotional materials, recruitment, and assignment of students to halls. Third, interventions should be varied and developmentally appropriate. Fourth, freedoms should be balanced with responsibility.

\section{Peer-Enhanced Motivational Interviewing for College Student Drinking}

Tracy A. O'Leary, Peter M. Monti, and Suzanne M. Colby According to recent national surveys, rates of excessive alcohol use in late adolescence are a cause for concern. Among college students, 39-44\% are classified as heavy drinkers (Johnston et al., 1997; Presley et al., 1996), and $38 \%$ report heavy drinking episodes in the past 2 weeks (Johnston et al., 1997). Indeed, the transition of students from high school to freshman year of college is associated with substantial increases in alcohol use (Baer et al., 1995). Excessive alcohol use in college is also associated with numerous adverse social consequences, such as getting into trouble with police, damaging property, sustaining injuries, driving after drinking, decrements in academic performance, eating disorders, engaging in risky/unwanted sexual activity, and sexual assault (Koss et al., 1987; Krahn et al., 1992; Wechsler et al., 1994; Wechsler and Isaac, 1992). Social influences on drinking behavior typically begin in early adolescence, with peers exerting a powerful effect on subsequent substance use involvement (e.g., Wills et al., 1996a,b). By the time adolescents begin college, peer relationships become their primary social support network, and peer exposure significantly affects drinking levels (Baer, 1994). Alcohol consumption tends to occur in social contexts (Humphreys et al., 1997) and is often part and parcel of the college experience (Nezlek et al., 1994). College drinking is also reinforced by the institutionalized nature of the college environment (Rabow and Duncan-Schill, 1995). Indeed, the well established link between social network support for drinking and drinking rates among adults (e.g., Longabaugh et al., 1998; Project MATCH Research Group, 1997) speaks to the importance of taking social factors into account when designing interventions.

Brief interventions, such as motivational interviewing, have demonstrated success in reducing alcohol use and alcohol-related problems in adolescents and college students (e.g., Borsari and Carey, 2000; Marlatt et al., 1998; Monti et al., 1999) but have been limited mainly to individual formats that generally do not address social factors. However, Marlatt et al. (1998) speculate that part of the success of their motivational approach was due to a focus on contextual and social factors, matched to students' lifestyles, that affected alcohol use, such as living in fraternities or sororities, alcohol use by peers, and drinking and dating. To further improve treatment outcome and to directly address the implications of the social network literature, we conducted a pilot study to compare the efficacy of individual motivational interviewing (IMI) versus peer-enhanced motivational interviewing (PMI) in reducing subsequent alcohol use rates among college students mandated to receive alcohol education for alcohol-related infractions of university policies. In light of the successes of behavioral marital therapy (O'Farrell, 1994) and relationship enhancement therapy for alcohol abuse (Longabaugh et al., 1995), we hypothesized that involving peers (primarily friends of the students) in an alcohol intervention would increase intervention effectiveness by enhancing social support for changing alcohol use. We also hoped to capitalize on students and peers making a public commitment during the intervention to help each other change problematic drinking, because making public commitments to change increases the likelihood of adherence to goals (e.g., Karuza et al., 1995; Parrott et al., 1998). Both the IMI and PMI protocols were consistent with the motivational principles outlined in Miller and Rollnick (1991a).

The study was conducted at a large, private 4-year university in the Northeast. The Offices of Residential Life referred students who had alcohol-related infractions of university policy to the study as part of their mandatory alcohol education program, with students having the option to participate in the study in lieu of paying a US\$50 fine for the alcohol-related infraction. Study treatment providers screened and recruited eligible students, i.e., those who were between 18 and 24 years old, spoke English, were enrolled full-time at the university, and were mandated to receive alcohol education for an alcohol-related infraction. After informed consent, a 45-min assessment battery was administered to students within a week of recruitment. Assessment measures included demographics, the Important People Instrument (Longabaugh and Zywiak, 1998), the Adapted Short Michigan Alcoholism Screening Test for Fathers and Mothers (Selzer et al., 1976; Sher and Descutner, 1986), the Timeline Follow-Back Interview (Sobell and Sobell, 1992, 1995), the Young Adult Alcohol Problems 
Screening Test (Hurlbut and Sher, 1992), and the Strategies to Limit Drinking Questionnaire (Werch, 1990).

During the assessment, students were asked to identify a peer of the same gender who would be willing to participate in the study. To ensure that the nature of the student-peer relationship was stable, meaningful, and positive (versus casual or that of acquaintances), we screened for the level of investment in the relationship with the nominated peer by using the Important People Instrument. Nominated peers were eligible to participate if they were 18 to 24 years old; they were not a current or former significant other of the student; they were the same gender as the student; the student reported seeing the peer at least once a week; the student rated the peer as important, very important, or extremely important to them; and the student rated the peer as supportive, very supportive, or extremely supportive of the student. After completing baseline assessment with the student, the treatment provider then contacted eligible peers, recruited them into the study, and conducted the same baseline assessment battery with peers. To ensure the confidentiality and fidelity of responses, students and peers were assessed independently. Students were then randomly assigned to either IMI or PMI. Peers were matched to the student's intervention condition. Specifically, for students randomized to IMI, the peer did not participate in the intervention (i.e., peers completed assessment only), whereas for students randomized to PMI, the student and peer participated together in the intervention (i.e., peers completed the assessment and were present with the student during the intervention).

Within a week of the assessment, the IMI sessions were conducted with the student. In the first IMI session (approximately $30 \mathrm{~min}$ ), the treatment provider first established rapport with the student, assessed his or her motivation for changing alcohol use behavior, and explored the student's perceived positive and negative consequences of the alcohol use. In the second IMI session ( $45 \mathrm{~min})$, the student received a personalized feedback form based on assessment data. This feedback included a comparison of the student's alcohol use with age- and gender-matched norms, social and familial effects of alcohol use, risks of continued alcohol use in the future, and financial costs of alcohol use. Finally, the treatment provider helped the student set goals for alcohol use behavior change, explore barriers to change, and provide strategies and advice to deal with barriers when appropriate. The treatment provider gave the student an in-depth informational handout on various negative consequences and facts related to alcohol use, a handout on strategies for dealing with urges to use alcohol, and a handout listing goals for changing alcohol use behavior.

In the PMI condition, the contents of the first PMI session were identical to those of the first IMI session, and the treatment provider met individually with the student. However, in the second PMI session, both the student and his or her peer attended the session. In this second session, the treatment provider established rapport with both the student and peer and assessed their motivation for changing alcohol use behavior. Students and peers each received a personalized feedback form based on assessment data, as described previously. Finally, the treatment provider helped both the student and peer set goals for reducing alcohol use, explored barriers to change, and provided strategies and advice to deal with barriers when appropriate. Both the student and peer were asked to generate ways in which they could support each other's goals around changing drinking. Students and peers in both intervention conditions were assessed independently at a 1-month follow-up.

In this presentation, we focused on the results on alcohol consumption rates of students from baseline to 1-month follow-up. We reported preliminary results from 29 students (10 women and 19 men) and 29 of their gendermatched peers with complete baseline assessment data; 1-month follow-up assessments were completed with $83 \%$ of students and $93 \%$ of peers. The mean age of the students was $19.1 \pm 1.4$ years, and for peers, the mean age was 19.1 \pm 1.6 years. Seventy-seven percent of students and $81 \%$ of peers were freshmen; $71 \%$ of the sample was male. The majority of students and peers were full-time students living on campus at the same university, and most peers were classified as either friends or close roommates of the students. Students and peers demonstrated significant positive correlations at baseline on percentage of drinking days in the past month, average number of drinks per drinking day, and percentage of heavy drinking days in the past month (defined as four or more drinks per occasion for women and five or more for men).

Multivariate analyses of covariance, with baseline level of alcohol use days as a covariate, were conducted to compare IMI with PMI on the percentage of alcohol use days and the percentage of heavy drinking days (defined as four or more drinks per occasion for women and five or more for men) at the 1-month follow-up assessment, by using the 30-day Timeline Follow-Back Interview. For the percentage of drinking days, there was a significant effect of time $(p<0.03)$, with no between-group differences: students in both IMI and PMI reported significant reductions in drinking from baseline to follow-up. A similar pattern arose for percentage of heavy drinking days in the past month: there were significant main effects for time $(p<0.01)$, with no significant differences between groups. On the basis of these preliminary data, students in both interventions seemed to be decreasing the overall number of drinking days as well as heavy drinking episodes from baseline to follow-up.

In light of recent concerns aired about the potential iatrogenic effects of including peers in interventions (cf Dishion et al., 1999), multiple regression analyses were performed with number of heavy alcohol use days as the dependent variable to test whether the drinking level of the peer influenced student drinking rates at follow-up. Al- 
though students' baseline number of heavy drinking days significantly predicted heavy drinking days at follow-up, gender, intervention, and baseline heavy drinking days in peers did not significantly add to the variance accounted for by the model. Thus, heavier peer drinking levels at baseline did not seem to negatively affect the outcome for students.

Preliminary findings from this pilot study were encouraging in that students seem to benefit from both IMI and PMI in terms of reduced drinking days and heavy drinking days and that peer alcohol use does not seem to moderate outcome. Limitations include a small sample size, variability in the level of offense that caused the student to be referred to the study (ranging from possession of alcohol in a dorm room to severe intoxication), and a lack of a control group. Indeed, the involvement of peers at any level, including assessment, may have obscured differences between the two intervention conditions. Future directions include replicating with a larger sample, including a control condition, targeting peers with more moderate alcohol use levels at baseline to strengthen the PMI condition, and focusing on reducing risky behaviors associated with alcohol consumption.

\section{Alcohol Abuse Prevention in Fraternities and Sororities}

Mary E. Larimer, Jonathan S. Fader, Irene M. Geisner, Rebekka S. Palmer, and Jessica M. Cronce College students are among the nation's highest risk groups for experiencing problem alcohol use and alcohol use disorders. It is clear from the research literature that members of college Greek systems are at considerably increased risk for problem alcohol use (Alva, 1998; Wechsler et al., 1996). Unfortunately, fraternity and sorority members have also been found to be less likely to participate in, and benefit from, available alcohol prevention programs (Dielman, 1990).

In addition to such individual difference factors as drinking history (Baer et al., 1995; Larimer et al., 2000), positive expectations for alcohol's effects (Cashin et al., 1998), and low motivation to change (Goodwin, 1989), heavier drinking by members of Greek organizations has been linked to a variety of peer and normative influences (Baer et al., 1991; Goodwin, 1989; Larimer et al., 1997). These include inflated perceptions of normative drinking patterns within Greek organizations, overestimations of the acceptability of drinking, and actual peer support for and modeling of high-risk alcohol use. Particularly for fraternities, alcohol use has been found to be a positive aspect of house reputation and popularity (Larimer et al., 1997). Consistent with social learning theory (Bandura, 1986), the overestimation of norms for drinking, combined with the modeling of actual heavy drinking within Greek organizations, has been suggested to be a significant barrier to individual change in heavy-drinking Greek houses.

Taken together, these findings suggest that effective interventions for Greek drinking should target motivation to change, increased accuracy of norms and perceptions, de- creased peer influences to drink heavily, decreased perceptions of alcohol's socialization value, and increased visibility of light-drinking or nondrinking peers. This research evaluated the efficacy of a brief intervention designed to directly target each of these, through a combination of implementation strategy, program content, program process, and program provider.

Specifically, we evaluated a brief motivational enhancement (Miller and Rollnick, 1991b) and skills training intervention (Dimeff et al., 1999), delivered individually to all willing members of intact pledge (entering) classes of randomly selected fraternities and sororities. The intervention included individualized feedback regarding campus norms for alcohol consumption, the percentile for each individual in comparison to local and national norms, expectancy and placebo effects of alcohol, personalized negative consequences, risk perception, motivation to change behavior, and tips for doing so, if relevant. The motivational feedback style encourages reflection, discussion, and individual decision-making about change. House-wide feedback was also presented, challenging the stereotype that all members drink heavily and emphasizing the broad range of actual drinking behavior (including the significant proportion of light or moderate drinkers and abstainers) and advantages to the house of reducing individual heavy drinking behavior. Finally, participants within intervention houses were randomly assigned to receive their individual feedback interview from a mental health professional (advanced doctoral student, masters' level therapist, or licensed clinical psychologist) or trained undergraduate peer providers. Although peer-based interventions have a long history on college campuses (Barnett et al., 1996; Schroeder and Prentice, 1998), intervention content is rarely disentangled from intervention provider, and thus prior research has led to widely divergent views regarding the efficacy of peer-led approaches. We hypothesized that the use of peers to provide the motivational feedback might enhance the intervention through providing direct experience with the fact that not all students drink heavily, nor do they support heavy drinking. We also anticipated that the use of peers might enhance the credibility of the skills-training information content.

In a prior article, we reported on the efficacy of the intervention for our first cohort of male participants (Larimer et al., 2001). This research is a replication and extension of those data, combining the original and a subsequent cohort of new male participants with three cohorts of female sorority members.

Participants were recruited from the incoming pledge classes of 28 fraternities and 17 sororities at a large West Coast university. Details of the recruitment and selection process are reported elsewhere (Larimer et al., 2001). For this research, 2 cohorts of pledge class members from each of 12 fraternities were included, as were 2 cohorts of pledge class members from each of 8 sororities, recruited over a 3 -year period. The total resulting sample consisted of 392 
men and 330 women; $82 \%$ of the men and $85 \%$ of the women were white, $11 \%$ were Asian/Pacific Islanders, and the remainder reported other ethnic identification.

Each fraternity or sorority was randomly assigned to either the intervention condition ( $n=6$ fraternities, $n=4$ sororities) or the assessment only/treatment-as-usual control group ( $n=6$ fraternities, $n=4$ sororities). Individual study participants completed the baseline assessment during the fall or winter quarters of their first year of fraternity or sorority membership, and follow-up assessment was 1 year after baseline. Measures included the Daily Drinking Questionnaire (Collins et al., 1985) to assess current drinking rates, the Rutgers Alcohol Problem Index (White and LaBouvie, 1989) to assess the prevalence of alcohol-related consequences, and the Alcohol Dependence Scale (Skinner and Horn, 1984) to assess the symptoms of alcohol dependence. We computed their estimated blood alcohol level by using an algorithm based on gender, weight, and the amount and rate of consumption for typical and peak drinking occasions (Dimeff et al., 1999).

Preliminary analyses with the combined cohorts largely replicate published findings regarding intervention efficacy for male participants from the first cohort (Larimer et al., 2001). Men in the intervention condition reported reductions in the overall amount of alcohol consumed in a typical week and peak blood alcohol level, compared with controls. Peers continued to be at least as effective as professional providers on all outcome measures. In addition, with the combined cohorts, significant advantages of peer providers emerged on 6-month and 1-month prevalence of short-term negative consequences from the Rutgers Alcohol Problem Index.

There were no main effects of the intervention for women. Instead, women in both the experimental and treatment-as-usual conditions reduced their consumption by an equivalent amount over time. In contrast to findings favoring peers for male participants, professional providers seem to have the advantage in working with women participants. Specifically, women who received their individual intervention from a professional provider reported significantly greater decreases in alcohol-related negative consequences than did those who received their intervention from a peer, and the trend was for professional providers to show greater improvement among their participants than peer providers across all outcome variables.

This research was designed to evaluate the efficacy of a brief motivational and skills-based intervention to prevent excessive alcohol use and related negative consequences among fraternity and sorority members. Preliminary results suggest that the intervention is effective for fraternity men, but less so for women. Results also suggest that men responded best to trained peer providers, whereas women seemed to benefit only if the provider was a professional.

Of note, women overall were more difficult to recruit and retain and were significantly less likely to complete the in-person intervention than were men; thus, some of the failure to detect overall advantages of the individual intervention in comparison to the group educational program incorporated into treatment-as-usual may stem from this lack of full implementation, rather than from a lack of efficacy per se. It has also been suggested that women in general may be more responsive to educational or other alcohol interventions, suggesting that the individual intervention was not a necessary component for women to change. Finally, the differential response to peer providers on the basis of participant gender warrants further study. Some research has suggested that women may be less influenced by peers with regard to alcohol consumption than are men (Larimer et al., 1997), and other research suggests that women may be more influenced by professional health care providers (Chick et al., 1988), either or both of which may explain these findings.

These results provide mixed support for broader implementation of the motivational enhancement and skillstraining intervention used here. However, given that fraternity members are the highest risk group on campus with regard to alcohol consumption and related negative consequences and given that peer providers seem to be superior to professionals in addressing these problems in fraternities, it seems that incorporating peer-led motivational interviews into standard practice within fraternities may be a viable and cost-effective alternative to standard educational approaches.

\section{Discussant Comments}

Barbara S. McCrady Each year, alcohol-related behavior results in the deaths of high school and college-aged students. Each individual death reverberates through the youth's family, friends, and community and results in calls for action to "do something" about youthful drinking. At the same time, drinking is imbued in youthful culture, and for many it is a defining rite of passage to adulthood. The circumstances of each death, of course, vary, but most are associated with drinking in a social context—at parties, sporting events, fraternities, or bars. Deaths of high school students may lead to community-based responses; alcoholrelated deaths of college students precipitate institutional responses-establishment of blue ribbon committees, examination of or development of campus alcohol policies, and the initiation of alcohol programs on the campus.

Despite the serious effects of youthful drinking and the thoughtful responses of communities and universities, youthful drinking and consequent problems continue. In fact, results are discouraging, because survey research shows no changes in the levels of drinking on college campuses over several decades. The challenges associated with youthful drinking to universities and high schools are substantial and complex. Issues of responsibility and the limits of the institution's responsibility for student behavior differ between high schools and colleges, but both must grapple with the boundaries among parental, individual 
student, and institutional responsibility. In colleges, living environments differ substantially, ranging from campus dorms to Greek letter organizations to off-campus housing, and university authority over these environments differs as well. There are also complex relationships between oncampus policies and the surrounding community, and changes in policy in one setting may have undesired effects in another sphere, because when campuses go dry, students drive into the communities to drink. Finally, high schools and universities themselves are part of larger communities that have a substantial voice in the institutions, but these voices are often conflicting, ranging from alumni who fondly recall and relive their college drinking experiences through homecoming and other reunion activities to legislators concerned about the use of tax dollars to support activities not considered part of the central academic mission.

Institutional responses largely fall into two categories: those at a policy level that target the overall institutional environment and those at an individual level that target the drinking of either all students or selected groups of students. Policy-level interventions include, among others, articulation of specific alcohol policies, regulation of access to alcohol, enforcement of alcohol policies, provision of alternative activities, and renorming campaigns. Individual-level interventions provide either universal information or targeted interventions for higher-risk youthful drinkers.

Given the multiple factors affecting institutional decision-making about alcohol, it is not surprising that scientific knowledge is only one of many voices guiding policy and programs, and, at times, it is a less influential voice than community, constituency group, or economic voices. Fortunately, scientific knowledge continues to advance, and as we know more about effective means to reduce high-risk drinking among youth, it is possible that the scientific voice may become more influential. The papers included in this symposium on social and developmental considerations in youthful drinking provide a new part of that scientific voice.

Two central themes bring the papers together-careful consideration of the developmental context within which youthful drinking and overdrinking occurs and particular consideration of the role of social influences in both the development of drinking patterns and interventions to change drinking among higher-risk youthful drinkers. Across all the papers, the developmental significance of peers looms large. Brown and D'Amico found that $80 \%$ of high school students taking advantage of a drinking information program sought out a group format, rather than either individual or Web-based formats, suggesting that discussion of drinking among peers is particularly appealing to this age group. An important caveat, however, was that youths from certain cultural backgrounds, particularly Hispanics and Asians, found the individual format more appealing. The findings of Larimer and her colleagues echo both of Brown and D'Amico's findings.
With college students, they found that peer-delivered interventions to reduce heavy drinking were particularly effective for men, but that college women responded better to professionally delivered interventions. Both studies suggest that capitalizing on the importance of peers may be important for some, but not all, youthful drinkers. O'Leary and her colleagues, however, found no particular benefit of involving peers in a targeted drinking-reduction intervention. However, her sample was small, and all had experienced alcohol-related infractions that may have more heavily influenced their subsequent drinking than the particular interventions provided. Finally, in a particularly provocative study, Maggs and Schulenberg suggest that individual values may guide youthful drinking more than peer influences and that individuals seek out peer influence groups that are consistent with their individual values and intents. Supporting their hypothesis was the very interesting finding that drinking in the spring semester of the freshman year of college did not differ between those who pledged Greek letter organizations and those who had wanted to pledge but did not (Wannabes). Although Maggs and Schulenberg's findings are particularly provocative, an important caveat is that the data were collected during the freshman year, and it is not clear whether students who had pledged a Greek letter organization were actually living in the Greek houses or associating more frequently with other Greeks than were the Wannabes. Later follow-ups when the groups are living in distinctly different environments will provide more definitive information.

How do these findings help institutions seeking to decrease negative alcohol-related events? First, the data suggest that college students interested in socializing and drinking seek out Greek letter organizations, clearly seeing them as settings for heavier drinking. Institutional interventions to both decrease drinking within these organizations and to change their image as drinking environments might be useful. Second, it seems that students will seek out alcohol-related information if it is readily accessible in their school environment and if it is offered in formats appealing to students. Group interventions should probably form an important component of alcohol-related programs, and these could be provided by well trained peer counselors or educators. Third, it is important to consider individual differences in providing programs and services, and both individually based services and professionally provided services should be available and equally accessible to students who prefer them. These data-based conclusions are consistent with many efforts in the high school and collegiate environment, and the authors should be encouraged to both continue their current programs of research and to consider ways to disseminate their findings in formats that are user-friendly for the institutions dealing with youthful drinking. 


\section{REFERENCES}

Alva SA (1998) Self-reported alcohol use of college fraternity and sorority members. J Coll Student Dev 39:3-10.

Arnold ME, Hughes JN (1999) First do no harm: adverse effects of grouping deviant youth for skills training. J School Psychol 37:99-115.

Ary DV, Tildesley E, Hops H, Andrews J (1993) The influence of parent, sibling, and peer modeling and attitudes on adolescent use of alcohol. Int J Addict 28:853-880.

Baer JS (1994) Effects of college residence on perceived norms of alcohol consumption: an examination of the first year in college. Psychol Addict Behav 8:43-50.

Baer JS, Kivlahan DR, Marlatt GA (1995) High-risk drinking across the transition from high school to college. Alcohol Clin Exp Res 19:54-61.

Baer JS, Stacy A, Larimer M (1991) Biases in the perception of drinking norms among college students. J Stud Alcohol 52:580-586.

Bandura A (1986) Social Foundations of Thought and Action: A Social Cognitive Theory. Prentice-Hall, Englewood Cliffs, NJ.

Barnett LA, Far JM, Mauss AL, Miller JA (1996) Changing perceptions of peer norms as a drinking reduction program for college students. $\mathrm{J}$ Alcohol Drug Educ 41:39-62.

Borsari B, Carey KB (2000) Effects of a brief motivational intervention with college student drinkers. J Consult Clin Psychol 68:728-733.

Breslin FC, Sdao-Jarvie K, Tupker E, Pearlman S (1999) First contact: A brief treatment for young substance users. Centre for Addiction and Mental Health, Toronto, Ontario.

Brown SA (1993) Recovery patterns in adolescent substance abuse, in Addictive Behaviors Across the Life Span (Baer JS, Marlatt GA, McMahon RJ eds), pp 161-183. Sage, Beverly Hills, CA.

Brown SA (2001) Facilitating change for adolescent alcohol problems: A multiple options approach, in Innovations in Adolescent Substance Use Intervention (Wagner EF, Waldron HB eds), pp 169-187. Elsevier Science, Oxford.

Cashin JR, Presley CA, Meilman PW (1998) Alcohol use in the Greek system: follow the leader? J Stud Alcohol 59:63-70.

Chick J, Ritson B, Connaughton J, Stewart A (1988) Advice versus extended treatment for alcoholism: a controlled study. Br J Addict 83:159-170.

Coie JD, Dodge KA (1998) Aggression and antisocial behavior, in Handbook of Child Psychology: Social, Emotional, and Personality Development (Damon W, Eisenberg N eds), pp 779-862. John Wiley, New York.

Collins RL, Parks GA, Marlatt GA (1985) Social determinants of alcohol consumption: the effects of social interaction and model status on the self-administration of alcohol. J Consult Clin Psychol 53:189-200.

D'Amico EJ, Fromme K (2000) Implementation of the risk skills training program: a brief intervention targeting adolescent participation in risk behaviors. Cogn Behav Pract 7:101-117.

D'Amico EJ, Metrik J, Brown SA (2001) Adolescent utilization of alcohol services: barriers and facilitators (abstract). Alcohol Clin Exp Res 25: 98A.

D'Amico EJ, Metrik J, McCarthy DM, Appelbaum M, Frissell KC, Brown SA (2001) Progression into and out of binge drinking among high school students. Psychol Addict Behav 15:341-349.

Deas D, Riggs P, Langenbucker J, Goldman M, Brown S (2000) Adolescents are not adults: Developmental considerations in alcohol users. Alcohol Clin Exp Res 24:232-237.

Dielman TE (1990) Prevention of Substance Abuse on the College Campus: A Summary of the Literature. Report prepared for the University of Michigan Task Force on Substance Abuse Prevention Committee.

Dimeff LA, Baer JS, Kivlahan DR, Marlatt GA (1999) Brief Alcohol Screening and Intervention for College Students (BASICS). Guilford Press, New York.

Dishion TJ, McCord J, Poulin F (1999) When interventions harm: peer groups and problems behavior. Am Psychol 54:755-764.
Goodwin L (1989) Explaining alcohol consumption and related experiences among fraternity and sorority members. J Coll Student Dev $30: 448-458$.

Humphreys K, Moos RH, Cohen C (1997) Social and community resources and long-term recovery from treated and untreated alcoholism. J Stud Alcohol 58:231-238.

Hurlbut SC, Sher KJ (1992) Assessing alcohol problems in college students. J Am Coll Health 41:49-58.

Johnston LD, O’Malley PM, Bachman JG (1997) National Survey Results on Drug Use From the Monitoring the Future Study, 1975-1995 (NIH Publication No. 98-4140). Vol. 2. US Department of Health and Human Services, Rockville, MD.

Johnston LD, O'Malley PM, Bachman JG (2000) National Survey Results on Drug Use From the Monitoring the Future Study, 1975-1999 (Vol. 1: Secondary School Students). US Department of Health and Human Services, Rockville, MD.

Karuza J, Calkins E, Feather J, Hershey CO, Katz L, Majeroni B (1995) Enhancing physician adoption of practice guidelines: dissemination of influenza vaccination guideline using a small-group consensus process. Arch Intern Med 155:625-632.

Koss MP, Gidycz CA, Wisniewski N (1987) The scope of rape: incidence and prevalence of sexual aggression and victimization in a national sample of higher education students. J Consult Clin Psychol 55:162-170.

Krahn D, Kurth C, Demitrack M, Drewnowski A (1992) The relationship of dieting severity and bulimic behaviors to alcohol and other drug use in young women. J Subst Abuse 4:341-353.

Larimer ME, Anderson BE, Baer JS, Marlatt GA (2000) An individual in context: predictors of alcohol use and drinking problems among Greek and residence hall students. J Subst Abuse 11:53-68.

Larimer ME, Irvine DL, Kilmer JR, Marlatt GA (1997) College drinking and the Greek system: examining the role of perceived norms for high-risk behavior. J Coll Student Dev 38:587-598.

Larimer ME, Turner AP, Anderson BK, Fader JS, Kilmer JR, Palmer RS, Cronce JM (2001) Evaluating a brief alcohol intervention with fraternities. J Stud Alcohol 62:370-380.

Liddle HA, Dakof GA (1995) Family-based treatment for adolescent drug use: state of the science, in Adolescent Drug Abuse: Clinical Assessment and Therapeutic Interventions (NIH Publication No. 95-3908) (Czechowicz ERD ed). National Institute on Drug Abuse, Rockville, MD, pp 215-254.

Longabaugh R, Wirtz PW, Beattie MC, Noel N, Stout R (1995) Matching treatment focus to patient social investment and support: 18-month follow-up results. J Consult Clin Psychol 63:296-307.

Longabaugh R, Wirtz PW, Zweben A, Stout RL (1998) Network support for drinking, Alcoholics Anonymous and long-term matching effects. Addiction 93:1313-1333.

Longabaugh R, Zywiak W (1998) Important People Instrument. Center for Alcohol and Addiction Studies, Brown University, Providence, RI (available by request from the first author).

Maggs JL (1997) Alcohol use and binge drinking as goal-directed action during the transition to university, in Health Risks and Developmental Transitions During Adolescence (Schulenberg J, Maggs JL, Hurrelmann K eds), pp 345-371. Cambridge University Press, New York.

Marlatt GA, Baer JS, Kivlahan DR, Dimeff LA, Larimer ME, Quigley LA, Somers JM, Williams E (1998) Screening and brief intervention for high-risk college student drinkers: results from a two-year follow-up assessment. J Consult Clin Psychol 66:604-615.

Miller WR, Rollnick S (1991a) Motivational Interviewing: Preparing People to Change Addictive Behavior. Guilford Press, New York.

Miller WR, Rollnick S (1991b) Motivational Interviewing: Preparing People for Change. Guilford Press, New York.

Monti PM, Colby SM, Barnett NP, Spirito A, Rohsenow DJ, Myers M, Woolard R, Lewander W (1999) Brief intervention for harm reduction with alcohol-positive older adolescents in a hospital emergency department. J Consult Clin Psychol 67:989-994. 
Nezlek JB, Pilkington CJ, Bilbro KG (1994) Moderation in excess: binge drinking and social interaction among college students. J Stud Alcohol 55:342-351.

O'Farrell TJ (1994) Marital therapy and spouse-involved treatment with alcoholic patients. Behav Ther 25:391-406.

Parrott R, Monahan J, Ainsworth S, Steiner C (1998) Communicating to farmers about skin cancer: the behavior adaptation model. Hum Commun Res 24:386-409.

Presley CA, Meilman PW, Cashin JR (1996) Alcohol and Drugs on American College Campuses: Use, Consequences, and Perceptions of the Campus Environment, Vol. IV: 1992-94. Core Institute, Southern Illinois University at Carbondale, Carbondale, IL.

Project Match Research Group (1997) Matching Alcoholism Treatments to Client Heterogeneity: project MATCH posttreatment drinking outcomes. J Stud Alcohol 58:7-29.

Rabow J, Duncan-Schill M (1995) Drinking among college students. J Alcohol Drug Educ 40:52-64.

Schroeder CM, Prentice DA (1998) Exposing pluralistic ignorance to reduce alcohol use among college students. J Appl Soc Psychol 28: $2150-2180$

Schulenberg J, Maggs JL (2002) A developmental perspective on alcohol use and heavy drinking during adolescence and the transition to young adulthood. J Stud Alcohol, in press.

Selzer M, Vinokur A, Van Rooijen LA (1976) A self administered Short Michigan Alcoholism Screening Test (SMAST). J Stud Alcohol 36:117126.

Sher KJ, Descutner C (1986) Reports of parental alcoholism: reliability across siblings. Addict Behav 11:25-30.

Skinner HA, Horn JL (1984) Alcohol Dependence Scale (ADS) User's Guide. Addiction Research Foundation, Toronto.

Sobell LC, Sobell MB (1992) Timeline followback: a technique for assessing self-reported ethanol consumption, in Measuring Alcohol Consump- tion: Psychosocial and Biological Methods (Allen J, Litten RZ eds), pp 41-72. Humana Press, Totowa, NJ.

Sobell LC, Sobell MB (1995) Alcohol Timeline Followback Users' Manual. Addiction Research Foundation, Toronto, Canada.

Stice E, Myers MG, Brown SA (1998) A longitudinal grouping analysis of adolescent substance use escalation and de-escalation. Psychol Addict Behav 12:14-27.

Wagner ES, Brown SA, Monti P, Myers MG, Waldron HB (1999) Innovation in adolescent substance abuse and prevention. Alcohol Clin Exp Res 23:236-249.

Wechsler H, Davenport A, Dowdall G, Moeykens B, Castillo S (1994) Health and behavioral consequences of binge drinking in college: a national survey of students at 140 campuses. JAMA 272:1672-1677.

Wechsler H, Isaac N (1992) 'Binge' drinkers at Massachusetts colleges: prevalence, drinking style, time trends, and associated problems. JAMA 267:2929-2931.

Wechsler H, Kuh G, Davenport A (1996) Fraternities, sororities and binge drinking: results from a national study of American colleges. Natl Assoc Student Personnel Adm 33:260-279.

Werch CE (1990) Behavioral self-control strategies for deliberately limiting drinking among college students. Addict Behav 15:119-128.

White HR, Labouvie EW (1989) Towards the assessment of adolescent problem drinking. J Stud Alcohol 50:30-37.

Wills TA, Mariani J, Filer M (1996a) The role of family and peer relationships in adolescent substance use, in Handbook of Social Support and the Family (Pierce GR, Sarason BR, Sarason IG eds), pp 521-549. Plenum, New York.

Wills TA, Vaccaro D, McNamara G, Hirky AE (1996b) Escalated substance use: a longitudinal analysis from early to middle adolescence. $\mathrm{J}$ Abnorm Psychol 105:166-180.

Windle M, Miller-Tutzauer C, Barnes GM, Welte J (1991) Adolescent perceptions of help-seeking resources for substance abuse. Child Dev 62:179-189. 